\title{
Summary of: Ethnic disparities in the oral health of three- to four-year-old children in East London
}

FULL PAPER DETAILS

1 Institute of Dentistry, Barts and The London School of Medicine and Dentistry, Queen Mary University of London; ${ }^{2 N H S}$ East London and the City ${ }^{*}$ Correspondence to: Professor Wagner Marcenes

Email:w.marcenes@qmul.ac.uk; Tel: +44 (0) 2078828650 Refereed Paper Accepted 13 March 2013 DOI: 10.1038/sj.bdj.2013.687 ${ }^{\circ}$ British Dental Journal 2013; 214: E4

\author{
W. Marcenes, ${ }^{* 1}$ V. E. Muirhead, ${ }^{1}$ S. Murray, ${ }_{1}^{2}$ P. Redshaw, ${ }^{2}$ \\ U. Bennett ${ }^{2}$ and D. Wright ${ }^{1,2}$
}

\begin{abstract}
Aim To report ethnic differences related to caries experience among three- to four-year-old children living in three of the most deprived boroughs in the UK in Inner North East London: Tower Hamlets, Hackney and Newham. Methods This cross-sectional survey used a cluster sampling study design following the British Association for the Study of Community Dentistry protocol. Twenty nurseries from each borough were randomly selected and all three- to four-year-old children in selected nurseries were invited to participate $(n=2,434)$. Calibrated dentists examined children. Demographic information was obtained from schools. Results One thousand, two hundred and eighty-five children were examined in 60 nurseries (response rate $=52.8 \%)$. Twenty-four percent of three- to four-year-old children had caries experience (mean $\mathrm{dmft}=0.92)$. Few children (2.1\%) had filled teeth. Children living in Hackney had significantly lower dmft scores (mean $=0.63)$ than children living in Newham (mean $=1.06)$ and Tower Hamlets (mean $=1.06)$. White European (mean = 1.91), Bangladeshi (mean $=1.05)$ and Pakistani $($ mean $=1.11)$ children had a significantly higher number of untreated carious teeth than White British children (mean $=0.56$ ). Conclusion Preschool children from a White Eastern European, Bangladeshi and Pakistani background are likely to experience significantly poorer oral health than their White British counterparts. These findings have profound implications for commissioning dental services and oral health promotion.
\end{abstract}

\section{EDITOR'S SUMMARY}

Imagine one hundred people gathered in a large town hall - 80 of this group are teachers, 6 are bankers, 2 are chefs, 5 dentists, 3 doctors, 2 solicitors and 2 Formula 1 drivers. Someone then enters the hall and declares that the people there must set taxes for the whole country. They assign tax bands by profession rather than by salary level and they are only allowed to set three different bands. I know this all sounds like a bizarre (and faintly ridiculous) reality TV show but bear with me.

Now, the teachers in the hall are definitely in the majority. They may just see the others in the hall as a minority group, the 'non-teachers'. A zero percent tax rate for the teachers perhaps? The group are also likely to look at the dentists and the doctors and lump them together as 'healthcare professionals'. If you were one of the dentists in the hall I suspect you would be annoyed by this. Indeed, even the five dentists themselves are likely to be diverse in the nature of their practice and interests. Is it appropriate in this instance for the 'minority' groups to essentially be treated as one or two lots of people to be dealt with? They will have different requirements, habits and outlooks. They will most certainly all have different personalities.

However, we do this all the time. We lump ethnic minorities together purely because they may lie in the same socioeconomic group. It is logical in many ways; they are a minority after all but will the groups within the minority have the same problems or responses? When deciding how to target healthcare to minorities perhaps it makes sense to break this habit and find out more about the people themselves, ie the minorities within the minorities.

The authors of this BDJ study do just this. They looked at 1,285 three- to fouryear-old children living in three of the most deprived boroughs in England and break down the typical 'Asian', 'White' and 'Black' minority groupings. It transpires, from this small sample, that White East European children appear to have a significantly higher level of untreated caries than White British children. Within the 'Asian minority' the authors found that Asian Pakistani and Asian Bangladeshi children had a significantly higher caries problem than Asian Indian pre-school children.

These are findings which could lead to more effective oral health promotion and dental services in deprived areas of the UK - which could result in better oral health for preschool children in the area as well as cost savings in the long term.

The full paper can be accessed from the $B D J$ website (www.bdj.co.uk), under 'Research' in the table of contents for Volume 215 issue 2.

\section{Ruth Doherty} Managing Editor

DOI: 10.1038/sj.bdj.2013.715 
TO ACCESS THE BDJ WEBSITE TO READ THE FULL PAPER:

- BDA Members should go to www.bda.org.

- Click the 'login' button on the right-hand side and enter your BDA login details.

- Once you have logged in click the 'BDJ' tab to transfer to the BDJ website with full access.

IF YOUR LOGIN DETAILS DO NOT WORK:

- Get a password reminder: go to www.bda.org, click the login button on the right-hand side and then click the forgotten password link.

- Use a recommended browser: we recommend Microsoft Internet Explorer or Mozilla Firefox.

- Ensure that the security settings on your browser are set to recommended levels.

IF YOU HAVE NOT YET SIGNED UP TO USE THE BDA WEBSITE:

- Go to www.bda.org/getstarted for information on how to start using the BDA website.
IN BRIEF

- Findings will have profound implications for the commissioning of dental services and oral health promotion.

- Demonstrates a disparity between the oral health of Whites, Blacks and Asians.

- Reports that preschool children a White Eastern European background are at significantly higher risk of developing caries and having untreated caries than children from any other ethnic group.

\section{COMMENTARY}

This very welcome paper reminds us of the pain that caries still causes today and it is excellent to see our established dental surveys used to highlight UK dental health inequalities. The field work was six years ago at the time of the recession and before the austerity measures we currently enjoy! As a result dental health inequalities may have now become even worse in these three London boroughs; it is less than five miles from Tower Hamlets Town Hall to the Bank of England HQ!

The word 'disparities' from the title is often seen as value free, perhaps to avoid stigmatisation or victim blaming, rather than focusing our attention on the relentless, entrenched differences caused when ethnic minorities, women, the poor or other groups who persistently experience social disadvantage and discrimination, experience worse health than more advantaged groups.

The low response rate is a concern and begs the question, 'what about the half who didn't respond?' The authors report collection of date of birth, parent's ethnicity and post-code. If collected for the original 2,434 randomly selected children a check might have been made between responders and non-responders for any bias. Mean $\mathrm{dmft}$ increases with age and it would be good to see the mean ages and ranges of the groups; again this may have been undertaken but is not mentioned. The Index of Multiple Deprivation (IMD) might have allowed an analysis to show any interaction with ethnicity. Are some ethnic groups in reality a marker for poverty as the authors referenced in the their introduction?

The authors correctly reference the BASCD guidance quoting a random probability sample of 250-300 subjects in each reporting area, but then analyse the sample by the 13 results groups found across the three boroughs. This gives small numbers for each results group and methodological errors are likely as the authors themselves discuss. A cluster analysis of the individual nurseries in the sampling was mentioned but no results presented. Data was collected directly on to laptop computer and on paper; the paper would require subsequent recording on a computer with the potential for transcription errors, a potential quality assurance issue.

Despite these caveats, this study is very welcome for showing the stark differences in disease between groups of children defined by parental ethnicity. No one could disagree with the authors' conclusion that the findings do have profound implications for dental services to meet the needs of these groups and oral health promotion to prevent caries. One safe and effective intervention that would improve the dental health of all the affected children from inner North-East London regardless of poverty, class, or ethnicity is water fluoridation, which must surely be one practical conclusion from this study.

\section{Colwyn M Jones}

Consultant in Dental Public Health

NHS Health Scotland

91 Haymarket Terrace

Edinburgh EH12 5HE

\section{AUTHOR QUESTIONS AND ANSWERS}

1. Why did you undertake this research? Despite increasing ethnic diversity in the UK, we know little about ethnic disparity in oral health among pre-school children in the UK. Most previous studies on ethnic disparity have compared White ethnic groups with Black and Asian ethnic groups, which is likely to have masked relevant information for planning oral health services. Our previous research on adults in East London identified significant disparity within ethnic groups, which suggests that adopting a broader categorisation of ethnicity may uncover relevant disparity. Failing to acknowledge this disparity can mislead service providers and commissioners. Therefore, we decided to carry out this study and include a large sample with sufficient statistical power to disentangle relevant differences in oral health between specific ethnic groups.

\section{What would you like to do next in this} area to follow on from this work?

We have identified high levels of caries among White East European pre-school children as compared with children from other ethnic groups in the UK. Further research in this area will assess the impact of European migration on the UK dental health services. Another relevant finding was that Black and Asian Indian ethnic groups have similar or better dental health than White British children. Our further research in this area will aim to identify protective factors associated with good dental health. The information will be of great value for the development of oral health promotion interventions and will be tested in RCTs. 